Д.Г. Савинов; РАН. МАЭ им. Петра Великого (Кунсткамера). - СПб.: МАЭ РАН, 2014. - С. 263-283.

9. Карм С. Эхо Урала в эстонском национальном музее, или музеологический аспект эстонского концепта «Финно-угорский мир» // Ежегодник финно-угорских исследований. № 3, 2011. С.98-110.

10. Крылова И.В. Создание музейных экспозиций как способ передачи исторического знания // Триумф музея? СПб.: Осипов, 2005. С. 172-176.

11. Леви-Стросс К. Тотемизм сегодня. Неприрученная мысль / Пер. с фр. А.Б. Островского. М.: Академический Проект, 2008. 520 с.

12. Люба Мамонтова / Страница МФК им. Шемановского в Facebook. URL: https:// www.facebook.com/profile.php?id=100025498081306 (дата обращения 10.09.2019)

13. Музей козла в Tвери. URL: https://музей-козла.pф/ (дата обращения 10.07.2019)

14. Национальный музей Коми представил новый сайт и «утиный» фирменный стиль // БНК. Информационное агентство. URL: https://www.bnkomi.ru/data/news/ 49018/ (дата публикации 06.04.2016)

15. Пропn В.Я. Морфология <волшебной> сказки. Исторические корни волшебной сказки. (Собрание трудов В.Я. Проппа.) Комментарии Е.М. Мелетинского, А.В. Рафаевой. Сост., научная ред., текстол. коммент. И.В. Пешкова. М.: Лабиринт, 1998. 512 c.

16. Предметный разговор: культурно-просветительский портал. URL: http://portmvk. yanao.ru/portfolio/konkurs/ (дата обращения 10.07.2019)

17. Пчелянская Т.М. Музеи и музейные экспозиции в новом спектре сетевых коммуникаций // Триумф музея? СПб.: Осипов, 2005. С. 146-160.

18. Смородинова E. «Если государство здоровое, оно должно защищать красоту и художников». Интервью с Яном Фабром // Ведомости. URL: https://www.vedomosti. ru/lifestyle/characters/2017/10/20/738694-gosudarstvo-zdorovoe-hudozhnikov (дата публикации 19.10.2017)

19. Токарев С.А. Ранние формы религии. М.: Политиздат, 1990. 662 с

20. Цикл «Хохины сказки»// Официальный сайт Зоологического музея МгУ им.М.В. Ломоносова. URL: http://zmmu.msu.ru/posetiteli/interaktivnye-zanyatiya/ hohiny-skazki (дата обращения 10.08.2019)

21. Элькин А. Коренное население Австралии. М.: Изд-во иностранной литературы, 1952. $254 \mathrm{C}$.

22. McCarthy C. and Herring B. Museum \& Community Partnerships: Collaboration Guide. For museums working with community youth-serving organizations. 2015. URL: https://www.nisenet.org/sites/default/files/NISE\%20 Network\%20 Collaboration\%20Guide\%2011-20-2015\%20FINAL.pdf (дата обращения 09.09.2018)

23. Museology and the Sacred Materials for a discussion Ed. by François Mairesse. ICOFOM 2019. 242 p.

24. Museums and communities: Curators, Collections and Collaborations. Edited by Viv Golding and Wayne Modest. Bloomsbury Academic, 2016. 288 p.

\section{Ivan Grinko,}

PhD in History, Head of the Department for the museum

and tourism development, SAIC «MOSGORTUR» (Moscow),

igrinko@mosgortur.ru

\section{Museum totemism}

The article shows the relationship between two socio-cultural institutions: a museum and a totemism. Not only their symbolic proximity is examined. The materials from museum expositions and social networks show how the practices of totemism can be used in contemporary museum management to solve some urgent problems as building of museum community, working with local identity and strengthening corporate culture.

Keywords: museums, museology, totemism, museum anthropology, museum management museum branding, local identity, corporate culture

\section{Елена Ржевская}

\section{Индия в графике Николая Кочергина: «Ты светлый храм земли, хранительница тайны...»}

В связи с изучением влияния культуры народов Азии на отечественное искусство в статье рассматривается книжная графика Николая Кочергина, образно интерпре тирующего индийскую тему для детского восприятия.

Ключевые слова: книжная графика, детская книжная иллюстрация, культура Индии, Индийское восстание, сказка, стилизация, образ слона, художественное наследие образ Индии, Николай Кочергин

Индия - «Страна долин бескрайних, / Страна духовной силь / И небесной чистоты» (строки из стихотворения Н.К. Рериха) нашла свое отражение в творчестве выдающегося отечественного графика, художника книги, Николая Михайловича Кочергина (1897-1974). Это обусловлено в первую очередь тем, что прославленный мастер создавал иллюстрации к сказкам народов Азии, в том числе индийским. Однако первое обращение 
к теме произошло в связи с работой над исторической повестью Эммы Выгодской «Опасный беглец» (1948).

Книга вышла всего через три года после окончания Великой Отечественной войны и была животрепещущей темой, повествующей о борьбе индийского народа против иноземных поработителей.

Содержание «Опасного беглеца» отсылает к историческим событиям восстания сипаев против жестокой колониальной политики англичан: «Восстань, о, Индостан, восстань!.. Умри за родину, за веру отцов!» [5, с. 20].

Индийское восстание 1857-1859 было подавлено, однако оно положило конец господству Британской ОстИндийской компании, что привело к ее замене прямым правлением английской короны.

К работе над книгой Выгодской Николай Кочергин приступил, имея за плечами огромный опыт по иллюстрированию журналов, в том числе «Вокруг света» и «Мир приключений». Кроме того, нелегкое время первой половины XX века, на которое пришелся расцвет таланта мастера, отмечено двумя историческими вехами - революцией и Великой Отечественной войной. Лучшие графики этого периода были привлечены к созданию патриотических плакатов, среди них был и Кочергин. Мастерство рисоваль-

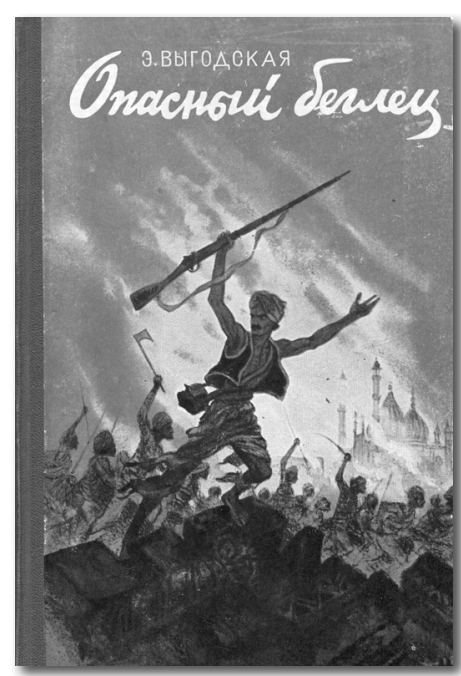

Н. Кочергин. Обложка книги Э. Выгодской «0пасный беглец щика, лаконичный язык высказывания на острую тему прослеживается в его агитационной графике.

Художественное чутье подсказало Кочергину выполнить композиционное решение обложки к книге «Опасный беглец» наподобие плаката. По точному определению крупного историка искусства, исследователя графики А.А. Сидорова, обложка «дает возможность увидеть и ознакомиться с книгою издали», что «зна чительно роднит обложку с плакатом» [10, с. 54]. Кочергин изобразил главного героя Инсур-Панду, призывающего к свободе своего Отечества. Ружье в его поднятой руке - характерный жест для героев агитационной графики на военную тему. Книга выдержала несколько переизданий (1956, 1960, 1963 гг.), художник несколько менял варианты обложки, но осталась прежней идея изображения персонажа исключительной духовной силы. Как известно, восстание сипаев началось на Севере от Бенгалии до Пенджаба и в Центральной Индии. Мужественным «Героям Бенгалии» Рабиндранат Тагор посвятил такие строки: «За poдину жертвуют люди собой, / Вступают они за религию в бой, / Расстаться готовъ они с головой / Во имя возвышенного идеала»; мастер исторической живописи В. Верещагин написал пронзительную картину «Подавление индийского восстания англичанами» (1884).

Для иллюстраций к книге художник выбирает ключевые моменты повести: сцены на Великом колесном 
пути в Индии - старинной дороге длинной свыше 2500 км, которая проходит по северной части Индийского субконтинента через Калькутту, Бенарес, Дели и Лахор; во дворце Бахадур-шаха, на узких улочках Старого Дели, в особняках колонизаторов и калькуттской тюрьме. Эмоционально переданы эпизоды героической обороны Дели и жестокой расправы с восставшими. В книгу, не считая обложки, вошло 30 иллюстраций, которые, несмотря на свою монохромность, в струящихся линиях перьевого рисунка, наподобие старой гравюры, передают природу, архитектуру, быт и костюмы сказочной для отечественного читателя восточной страны.

Одновременно повествование наполнено трагическими эпизодами, что усиливает выбранная художником черно-белая графическая манера. Исследователь творчества художника В. Матафонов справедливо писал о рисунках к этой книге: «Они увлекали своей эмоциональностью. Юный читатель узнавал в них интересные подробности. События знаменитого индийского восстания 1857-1859 годов ожили в иллюстрациях Кочергина» 6 , с. 5].

Николай Кочергин никогда не бывал в Индии. Окунуться в экзотическую атмосферу Востока ему удалось, когда в 1930 г. они вместе с писателем М.Е. Зуевым-Ордынцем были командированы в качестве специальных корреспондентов в Среднюю Азию, в 1938-м Кочергин побывал в Средней Азии вновь. Созданный художником после этой поездки станковый цикл «Старое и новое» (1938) имеет некоторые композиционные и стилистические аналогии с иллюстрациями к «Опасному беглецу».

Как интеллектуал, Кочергин прекрасно понимал, что Индия имеет свои исключительные этнографические особенности культуры и быта, поэтому разобраться в них, проникнуться духом «священных страниц» этой страны ему помогла научная литература и альбомы по искусству. Биограф художника подчеркивает, что во многом научный подход к теме обусловлен школой, которую он получил в Строгановском художественнопромышленном училище.

Многому он научился у своего педагога - Станислава Владимировича Ноаковского (1867-1928), читавшего лекции по истории искусства. Студенты Строгановского художественно-промышленного училища вспоминали, что Ноаковский был блестящим рисовальщиком «в стиле Гварди», ученики неделями не стирали с классной доски его виртуозные рисунки.

«Умение свободно разбираться в эпохах и стилях, воспитан ное Ноаковским, сослужило огромную службу Кочергину. Оно позволило ему в дальнейшем безукоризненно и точно передавать архитектуру, предметы быта, костюмы самых разных стран. Уроки Ноаковского выработали привычку просматривать альбомы, всевозможные увражи, справочники, знакомясь с которыми, художник постоянно пополнял свои знания» [6]. По свидетельству современников, с юности Кочергин стремился добыть понравившуюся книгу, и у него собралась крупная домашняя библиотека. Очевидно, окунуться в атмосферу индийской культуры ему помогли картины В.В. Верещагина, пейзажи Н.К. Рериха и дореволюционное издание Индийских сказок (1903 г.) с иллюстрациями Н.Н. Каразина, влияние классического рисунка которого прослеживается в работах Кочергина.

В пластическом и стилистических планах Кочергин многое перенял у старших представителей творческого объединения «Мир искусства»: И.Я. Билибина (18761942), С.В. Чехонина (1878-1936), Д.И. Митрохина (1883-1973), Н.Э. Радлова (1889-1942), поднявших художественное оформление книги на небывалую высоту. А.А. Сидоров подчеркивал: «Графика до революции 
в нашей книге проходила под знаком «Мира искусства»...» [9, с. 18]. По примеру «мирискуссников», иллюстрации Кочергина отличаются строгим композиционным построением, блестящим рисунком, тяготеющим к скульптурной пластике. От реалистической манеры и штриховой проработки в книжной графике он переходит к стилизации, которая имеет глубоко индивидуальные черты воздушности и легкости рисования одной контурной линией.

В «Опасном беглеце» сюжетные сцены Кочергин предпочитает изображать на фоне панорамных видов природы и архитектуры Индии, вслед за автором погружая юного читателя в атмосферу далекой страны и магического центра Азии - Дели, где в течение пяти тысячелетий пересекались многие торговые пути: «Арабские и тюрккские архитекторы строили его мечети, план его знаменитого двориа строил сам шах Джехан 1 . Этот город стоял и был славен, когда Лондона еще не было на свете, а Париж был только кучкой жалких глиняных хижин на берегу безымянной реки» [5, с. 20].

Этнографическое знание эпохи помогло художнику разобраться в традиционном костюме, подробно описанном Эммой Выгодской: «Обе женшины были в длинных, спускаюшихся до самых пят бельх широких юбках с узориатой каймой, в бельх шерстяных головных покрывалах-сари, низко закрывающих лоб и плечи» [5]. Одновременно в позах и пластике движений персонажей художник передает психологическую характеристику действующих лиц, порой противопоставляя характеры завоевателей - офицеров-саибов и угнетенных. Замечательные

\footnotetext{
${ }^{1}$ Шах Джахан I (1627-1658) («Повелитель мира»), обессмертивший свое имя постройкой Тадж-Махала. На вершине могущества, в 1648 году, Шах-Джахан перенес свою столицу из Агры в Дели, где им был построен город Шахджаханабад.
}

рисунки к книге воспроизводились в серии «Библиотека приключений и фантастики» и других переизданиях повести.
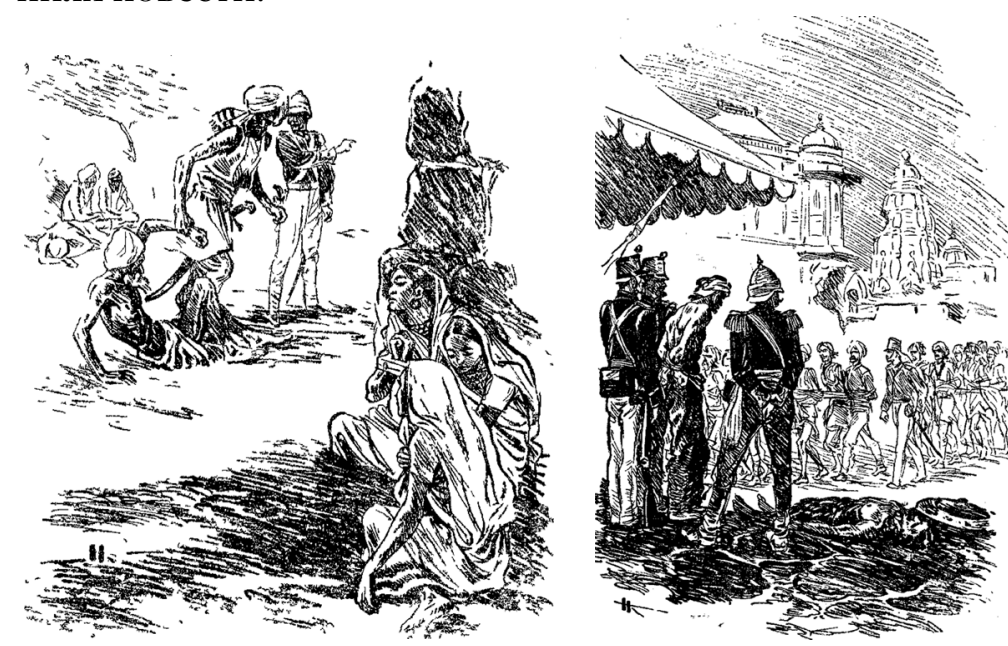

Иллюстрации Н. Кочергина к повести Э. Выгодской «0пасный беглец»

Юному поколению детей войны книга «Опасный беглец» давала возможность прикоснуться к истории другой страны, провести аналогии с недавними событиями своего Отечества, а благодаря иллюстрациям Кочергина визуализировать экзотический колорит Индии. Не менее интересной она осталась и для последующих поколений.

Иначе прозвучала индийская тема Кочергина в его работах над фольклорными произведениями литературы. В 1950-е гг. благодаря творческому союзу детского писателя и переводчика Нисона Александровича Ходзы (1906-1978) и Николая Кочергина читатели познакомились со «Сказками народов Азии».

«Волшебная чаша» (по мотивам индийских сказок) (1956) - первая книга из цикла восточных сказок. Сборник индийских сказок был переиздан в 1964 году. 
В 1959 году вышла общая - единая книга под названием «Сказки народов Азии», где были повторены многие тексты и иллюстрации. В 2016 г. эта книга переиздана издательством «Речь», в нее вошло 82 сказки с иллюстрациями Кочергина.

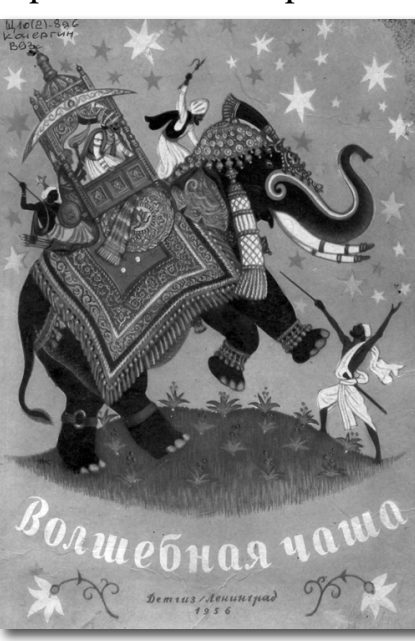

Н. Кочергин. Обложка книги сказок «Волшебная чаша»
Для обложки первого издания «Волшебной чаши» выбрана соответствующая сказке стилистическая манера, наполненная изяществом рисунка и тонкостью проработки деталей. А.А. Сидоров не случайно подчеркивал, что «допускается и миниатюрная трактовка» $[10$, с. 54]. Кочергин изображает драматически напряженную сцену: огромный слон, везущий раджу, встал на дыбы, главный герой угрожает пикой коварному правителю. Художник раскрывает, таким образом, смысл сказки о храбром воине Рамананде, смело в лицо говорящего своему врагу: «Кто любит, тот непобедим!» [4, с. 8]. Классическая точность изображения фигур действующих лиц сочетается здесь с условной стилизацией, ритмическим повторением мотивов: орнаментального узора, цветов и звезд. Богато убранство слона: на нем декорированные седло и повозка раджи, бивни и ноги слона украшены золотыми браслетами, на изогнутом хоботе красуется орнаментальный рисунок. Доспехи и латы свидетельствуют о том, что это боевой слон.

Слон в Индии - символ удачи и благополучия, его изображения можно встретить в качестве элемента ор-

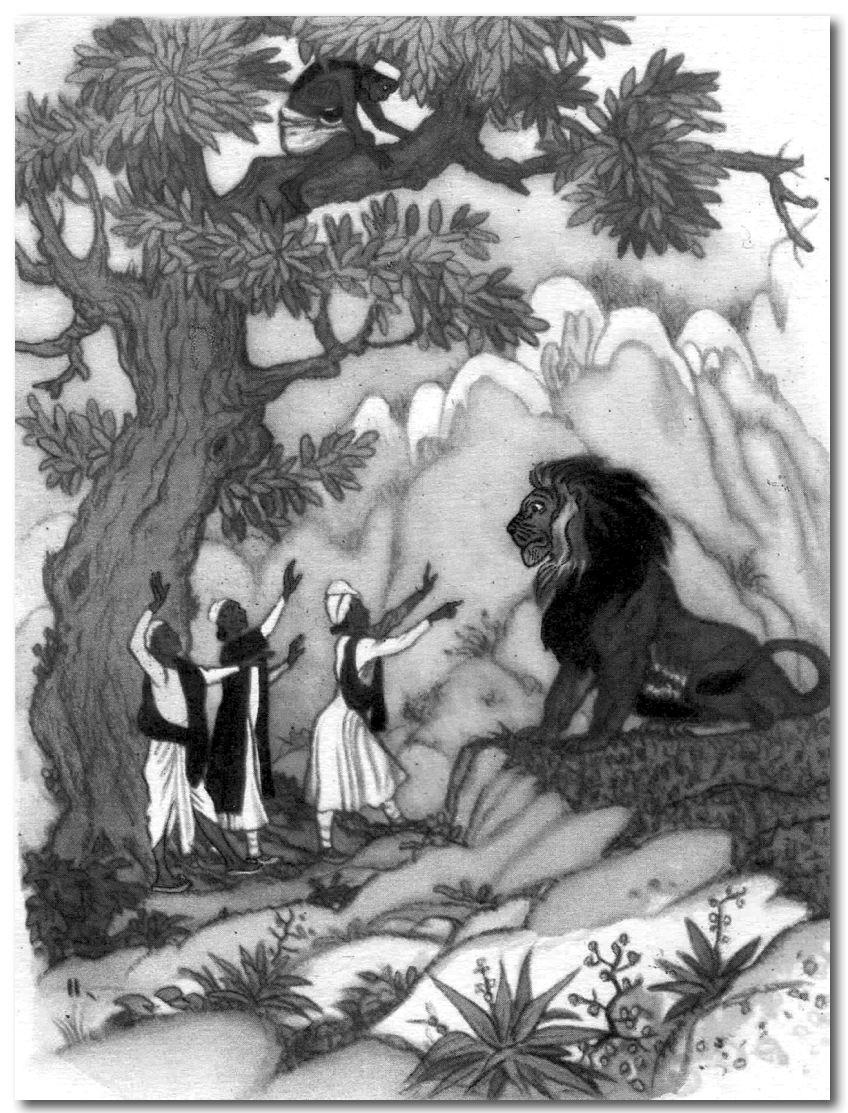

Иллюстрация Н. Кочергина к сказке «Ученые глупцы»

намента в храмах, в украшениях домов, со слоновьей головой предстает одно из божеств индуистского пантеона - Ганеша, бог мудрости и благополучия. Художник неоднократно обращается к изображению слона на страницах сказок, одна из которых посвящена этому прекрасному животному «На кого похож слон?». Золотистый фон обложки оттеняет название книги сказок, написанное белым цветом - символом чистоты и духовности; в белое одет воин Рамананд. 
По словам самого художника, личные детские впечатления наложили свой отпечаток на его сознание и воображение: «Я очень люблю страшные сказки...» [3, с. 23]. Однако никаких пугающих сцен художник не изображал, оставаясь в душе лириком, любящим детей и понимающем ранимую детскую психику. В иллюстрациях книги проявились элементы фантазии и грез, когда облако, к примеру, может превратиться в сказочный город или в слона.

Композиции графических листов отличаются остротой сюжета и психологической характеристикой героев в сочетании с фантастикой происходящего. Их характеризует большое разнообразие сюжетного ряда, где слоны пляшут, львы с достоинством ведут диалог с другими обитателями джунглей, герои мужественно сражаются, а звезды величиной с блюдце сияют на южном небе. В них в полную мощь раскрылся дар стилизатора, этнографа и фантазера в одном лице. Ю. Бычков тонко подметил: «Всегда эти рисунки на полах пронизывает добрый ласковый юмор. И стар и млад тянется к книжкам, иллюстрированным Н.М. Кочергиньм, еще и потому, ито они празднично декоративны» [1]. Это же можно отнести к заставкам, концовкам и буквицам. Как известно, Кочергин разрабатывал к своим книгам подробные тематические планы иллюстрирования [7, с. 234].

При этом Кочергин стремился в своих рисунках раскрыть для ребенка целый мир самобытной индийской культуры. Иллюстрации характеризует изображение многочисленных экзотических мотивов и бытовых подробностей: белокаменная архитектура украшена типичным декором из лепестков лотоса и завершается башенками или низкими куполами; интерьеры тяготеют к флористике и богатством орнаментального декора с резными ширмами, деревянной мебелью ручной ра-

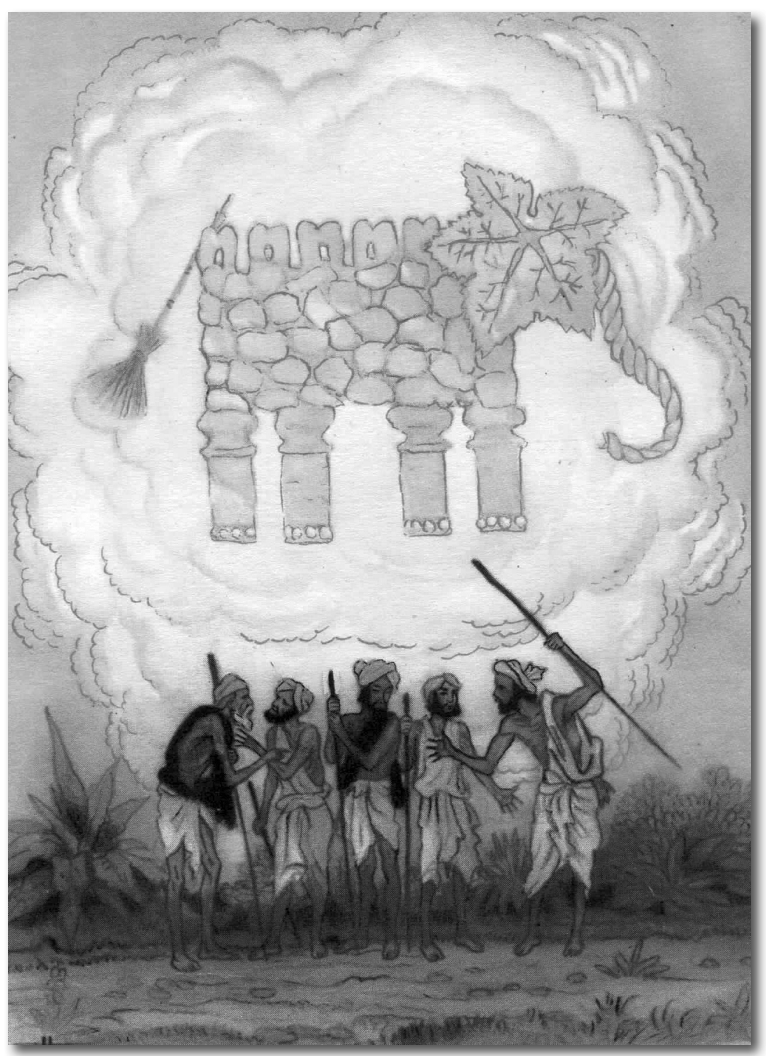

Иллюстрация Н. Кочергина к сказке «На кого похож слон»

боты, богатством фактурных тканей, изделиями из слоновой кости. И вся эта роскошь может быть передана у Кочергина одними контурными линиями второго плана композиций. Особенно живописно передана многообразная и уникальная природа Индии: величественные горные ландшафты, отвесные скалы, морские дали и «лесные, дрожащие чащи» с густыми древесными кронами и лианами, обвивающими стволы. Герои сказок имеют индивидуальную характеристику и предстают на фоне красок южной ночи или палящего 


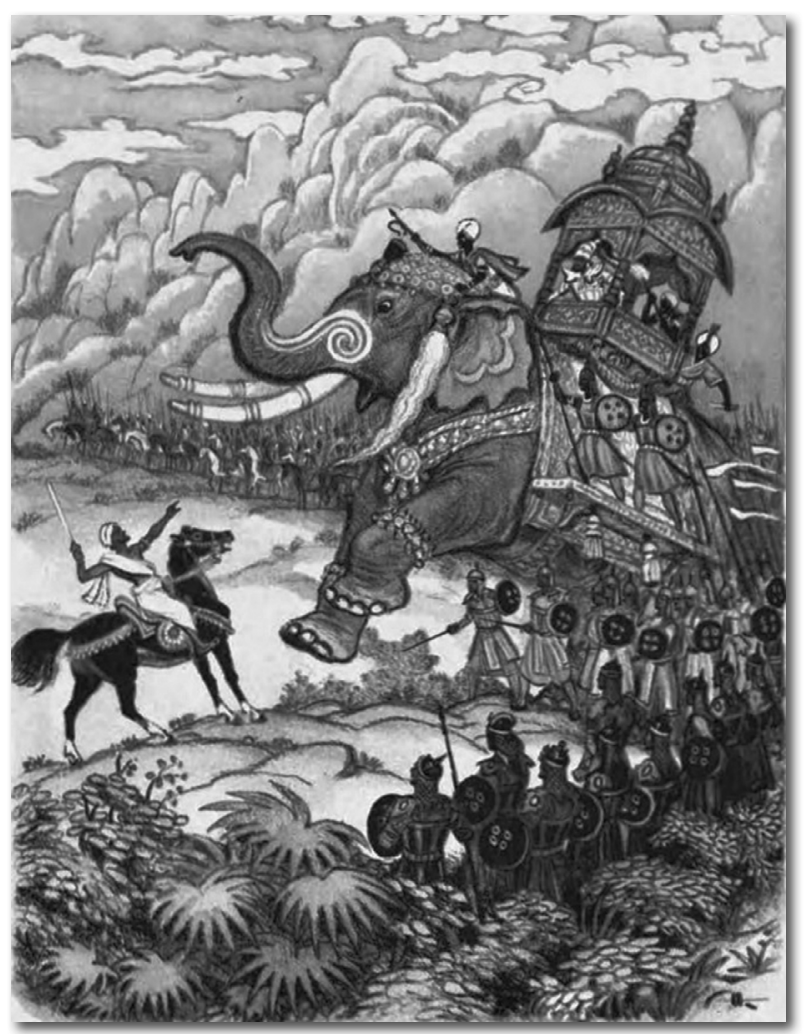

Иллюстрация Н. Кочергина к сказке «Купец и жестянщик»

солнца, преимущественно в окружении экзотических животных. Изображение зверей и птиц отличается большим мастерством, пластичностью и изяществом.

Кочергин глубоко осознал, что в основу философии индийской культуры заложено древнее представление о неразделимости природы и человека. Многие жанровые сцены, как свидание влюбленных, царский выезд на слонах, морские путешествия на джонках, несут в себе эту идею. Ключевым мотивом сказки о Рамананде стал корабль в виде галеры, который мчится по мор- ским волнам в поисках Счастливого города. Очень красив рисунок форзаца, передающий панорамный вид джунглей с лесными обитателями, речку с парусником и на дальнем плане селение с храмом, напоминающем храм Махабодхи (Великого Просветления) в Бихаре. В вышеупомянутой сказке есть описание храма Вишну, где «в двенадцатый день лунного месяца соберутся паломники со всех концов Индии» [4, с. 11].

Среди иллюстраций есть сцены выезда всадников на конях. В известных памятниках индийской миниатюры это часто используемая тема [8]. Вдохновленный ее лучшими образцами, Кочергин не упустил возможности проиллюстрировать сюжет сказки «Скупой раджа» и изобразить воинов-всадников в традиционных костюмах.

Выбранный художником золотисто-охристый колорит иллюстраций наполняет страницы с рисунками каким-то внутренним мягким свечением, словно окутывая их теплом далекой страны - «о, земля, сияющая в блеске солнца лучей» (слова Рабиндраната Тагора); деликатно подобрано соотношение между тушью и легкой акварельной подцветкой. О. Василиади, говоря о цикле «Сказок Азии», справедливо подметила: «Если же присмотреться к иветным иллюстрачиям восточных ска зок (а некоторые из них Кочергин выполнил именно в ивете), то непременно замечаешь не только сюжетные сиены, но и напоминаючие восточные шелковые свитки вертикальные пейзажные композииии» [2].

Погружаясь в атмосферу азиатской культуры, художник посещал этнографический музей в Ленинграде и специально съездил в Москву для изучения материала в Музее восточных культур. Глубокое проникновение в изучение искусства самой большой части света, омываемой тремя океанами, дали основание причислить 
художника к духовным ученикам Н.К. Рериха: «Кочергин может вполне подписаться под словами своего учителя Н.К. Рериха об исторической живописи "Для того чтобы историческал картина производила впечатление, необходимо, итобы она переносила зрителя в минувшую эпоху, для этого же художнику нельзя выдумъввать и фантазировать, надеясь на неподготовленного зрителя, а в самом деле надо изучать древнюю жизнь, как только возможно, проникаться ею, пропитываться насквозъ» [3]. Кроме того, любовь к сказке сближает этих художников, как известно, Н.К. Рерих сам сочинял стихи, сказки и картины иллюстрации к ним.

На время работы Кочергина над сказками народов Азии пришлось первое открытие персональной выставки Н.К. Рериха в выставочном зале Союза художников СССР в 1958 году. В этот период (вторая половина 1950-х - 1960-е гг.) Индия и СССР выстраивали партнерские отношения, став стратегическими союзниками. 15 августа 1947 г. состоялось провозглашение независимости Индии, вскоре было создано первое национальное правительство. В 1955 г. первый премьер-министр независимой Индии Джавахарлал Неру, вместе с дочерью Индирой Ганди посетил Советский Союз. В области культуры благодаря Н. К. Рериху были найдены точки соприкосновения в духовном плане, имманентно присущем двум цивилизациям. Величественное очарование Индии раскрывалось перед зрителями нашей страны в красочных монументальных полотнах Н.К. Рериха и более камерно, через сакральное пространство книги, в иллюстрациях Кочергина.

Николай Кочергин - художник-график «старой школы», расцвет которой пришелся на первую четверть XX века, он стал продолжателем ее традиций. Виртуозное мастерство рисовальщика сочетается у него с источниковедческим подходом к теме интерпретируемого периода. Как художник детской книги он известен благодаря своим уникальным иллюстрациям ко многим повестям, романам и сказкам.

Среди них мощным аккордом прозвучала индийская тема в визуализации сюжетов повести Э. Выгодской «Опасный беглец». Цикл «Сказки народов Азии» дает возможность сравнивать этнографические особенности культуры и быта этих стран, а иллюстрации к «Волшебной чаше» восходят к лучшим образцам индийской миниатюры, не теряя пластической связи с «мирискуссническими» заветами. Вслед за повествованием в них отражен главный смысл бытия: добро побеждает зло, влюбленные верны друг другу, восточная мудрость живет в веках, а юмор зажигает искру радости жизни. Книга как гармоничное соединение слова и рисунка, наполненная вдохновением и любовью художника, дает читателю полет фантазии и расширяет горизонты познания мира.

\section{Лumepamypa:}

1. Бычков Ю. Николай Кочергин и русская народная сказка... URL: https://red-balls. livejournal.com/120074.html (дата обращения 22.08. 2019)

2. Василиади 0. Сказочный дуэт. URL: http://www.fantastika3000.ru/node/4079 (дата обращения 26. 02. 2019)

3. Векслер Г. Жизнь, поиск, творчество // Художник. 1966. № 6.

4. Волшебная чаша. Л.: Детгиз, 1956. 160 c.

5. Выгодская Э. Опасный беглец. М.-Л.: Гос. изд-во Детской литературы, 1948. 256 с. 6. Матафонов В. Николай Михайлович Кочергин. М.: Художник РСФСР, 1978. 112 с.

7. Пахомов В.В. Книжное искусство. В 2 т. Т. 2. Иллюстрации. М.: Искусство, 1962. $432 \mathrm{c}$.

8. Рай Ананд Кришна. Индийская миниатюра //Индия Радуга. Нью-Дели: Бриажбаси Принтерс Пвт. Лтд, 1987.

9. Сидоров А.А. Графика. Книга III. М.-Л.: Искусство, 1949. 150 с.

10. Сидоров А.А. Искусство книги. М.: Дом печати, 1922. 100 с. 


\section{Helena A. Rzhevskaya}

PhD in Arts, Russian Academy of Arts,

Corresponding member (Moscow),

lrjevskaya@rah.ru

\section{India in Nikolai Kochergin's graphics:}

\section{«You are the bright Temple of Earth, the Keeper of Secrets...»}

In connection with the study of Asian culture influence on the domestic art, the article deals with Nikolai Kochergin's book graphics, figuratively interpreted Indian theme for children`s perception.

Keywords: Nikolai Kochergin, book graphics, children's book illustration, Indian culture, fairy tale, stylization, image of an elephant, artistic heritage, image of India

\section{В ПОРЯДКЕ ВЕЩЕЙ}

\section{Марина Кривенькая}

\section{«Дорогой, многоуважаемый шкап!»}

Автор новой рубрики альманаха «В порядке вещей» рассказывает о родословной знакомого всем предмета мебели - шкафа и его «родственников» - гардероба, буфета, сундука.

Ключевые слова: история повседневности, история вещей, интерьер, культура быта, история мебели

"Дорогой, многоуважаемый шкап! Привет ствую твое существование, которое вот уже больше ста лет было направлено к светлым идеалам добра и справедливости; твой молчаливый призыв к плодотворной работе не ослабевал в течение ста лет, поддерживая (сквозъ слезы) в поколениях нашего рода бодрость, веру в лучшее будушее и воспитьвая в нас идеаль добра и общественного самосознания»

(А.П. Чехов «Вишневый сад»)

Почтительное и благоговейное обращение к старому книжному шкафу Леонида Андреевича Гаева в первом

Кривенькая Марина

\section{Александровна,}

кандидат филологических наук, директор Центра регионоведения и гуманитарно-образовательного сотрудничества, дочент кафедры

культурологии, Институт социально-гуманитарного образования, Московский педагогический государственный университет (Москва), ma.krivenkaya@mpgu.su действии Чеховского «Вишневого сада» традиционно трактуется как образец напыщенности речей, сопровождающих торжественные моменты жизни и призванных придать событиям особенную значимость. Однако справедливости ради следует заме тить, что, приветствуя существование шкафа, чеховский герой, наделял его качествами, которые в полной мере 